This item was submitted to Loughborough's Institutional Repository (https://dspace.lboro.ac.uk/) by the author and is made available under the following Creative Commons Licence conditions.

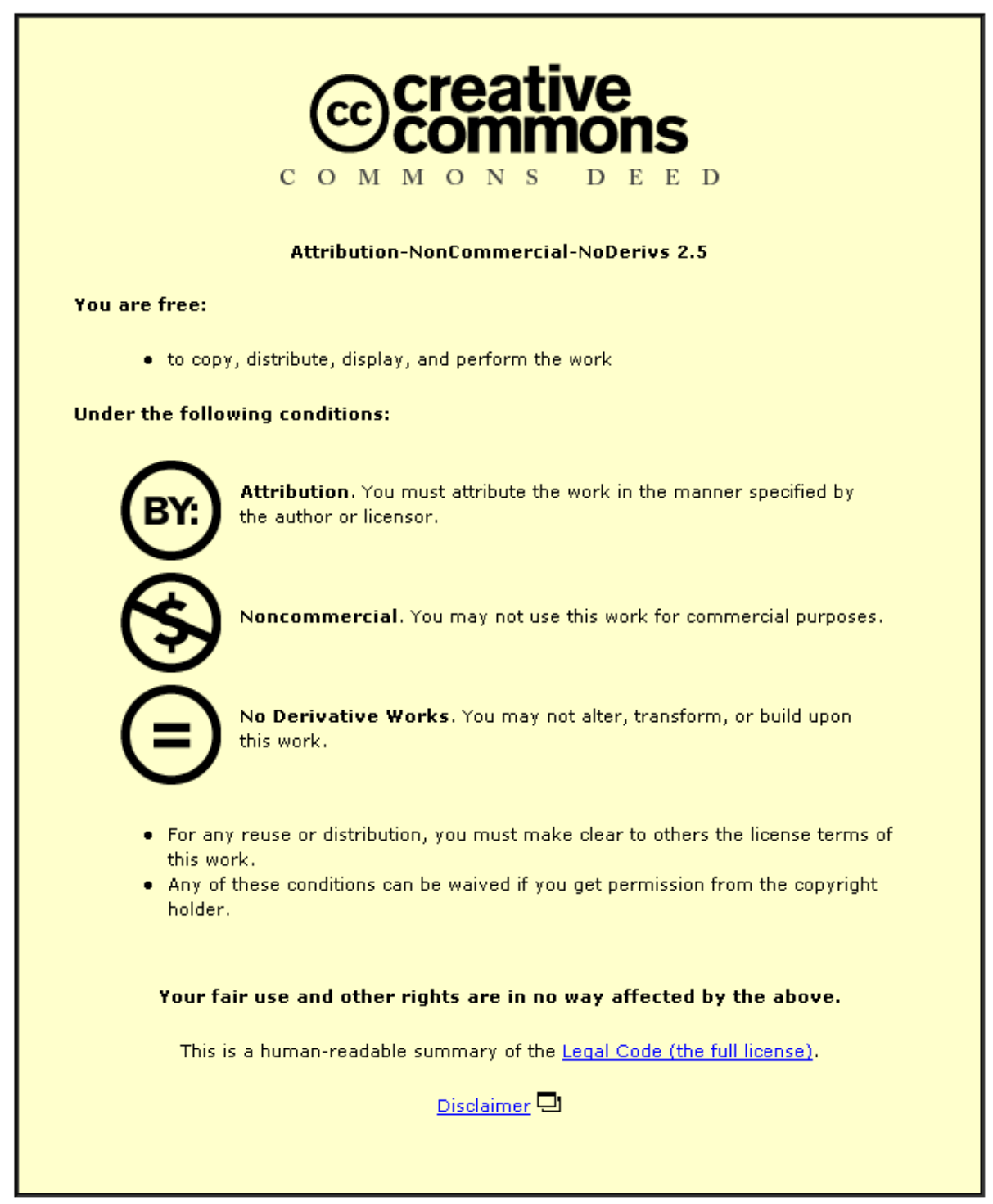

For the full text of this licence, please go to: http://creativecommons.org/licenses/by-nc-nd/2.5/ 


\title{
Regular Dark Chocolate Consumption's Reduction of Oxidative Stress and Increase of Free-Fatty-Acid Mobilization in Response to Prolonged Cycling
}

\begin{abstract}
Judith Allgrove, Emily Farrell, Michael Gleeson, Gary Williamson, and Karen Cooper
This study investigated the effects of regular consumption of dark chocolate (DC), rich in cocoa polyphenols, on plasma metabolites, hormones, and markers of oxidative stress after prolonged exhaustive exercise. Twenty active men cycled at $60 \%$ maximal oxygen uptake $\left(\mathrm{VO}_{2 \max }\right)$ for $1.5 \mathrm{hr}$, with the intensity increased to $90 \%$ $\mathrm{VO}_{2 \max }$ for a 30 -s period every $10 \mathrm{~min}$, followed by a ride to exhaustion at $90 \% \mathrm{VO}_{2 \max }$. In the $2 \mathrm{wk}$ before exercise participants consumed $40 \mathrm{~g}$ of DC or an isocarbohydrate-fat control cocoa liquor-free chocolate (CON) twice daily and once $2 \mathrm{hr}$ before exercise in a randomized, counterbalanced, crossover design. Venous blood samples were taken immediately before exercise, postexercise (fixed duration), postexhaustion, and after $1 \mathrm{hr}$ of recovery. $\mathrm{F}_{2}$-isoprostanes were significantly lower (post hoc tests: $p<.001$ ) at exhaustion and after $1 \mathrm{hr}$ of recovery with DC. Oxidized low-density lipoproteins were significantly lower with DC $(p<.001)$ both before and after exercise and at exhaustion. DC was also associated with $\sim 21 \%$ greater rises in free fatty acids during exercise (main effect: $p<.05$ ). Changes in circulating glucose, insulin, glucagon, cortisol, and interleukin (IL)-6, IL-10, and IL-1ra were unaffected by treatment. Time to exhaustion at $90 \% \mathrm{VO}_{2 \max }$ was not significantly different between trials ( $398 \pm 204$ and $374 \pm 194$ s for DC and CON, respectively). These results suggest that regular DC intake is associated with reduced oxidative-stress markers and increased mobilization of free fatty acids after exercise but has no observed effect on exercise performance.
\end{abstract}

Keywords: polyphenols, antioxidants, exercise, cocoa

Physical activity results in increased production of free radicals and other reactive oxygen species (ROS), primarily arising from elevated oxidative phosphorylation in the mitochondria of contracting skeletal muscle (Davies, Quintanilha, Brooks, \& Packer, 1982; Jackson, Pyne, \& Palomero, 2007). Other potential sources include plasma, blood cells such as erythrocytes and leukocytes, smoothmuscle cells, and endothelial cells (Nikolaidis \& Jamurtas, 2009). ROS can induce lipid and protein peroxidation, leading to oxidative stress, acute-phase inflammatory responses, and possible acceleration of muscle-fatigue development (Powers, Deruisseau, Quindry, \& Hamilton, 2004). Muscle cells can be protected from these ROS by a cooperative system of endogenous defense mechanisms in which antioxidants may play a role.

Supplementation with antioxidants has been proven effective in a number of studies at reducing the magnitude of the oxidative stress and inflammatory response that can occur after prolonged intense exercise, as well as limiting the degree of immunosuppression, although a

Allgrove, Farrell, and Gleeson are with the School of Sport, Exercise and Health Sciences, Loughborough University, Loughborough, UK. Williamson and Cooper are with the Bioanalytical Science Dept., Nestlé Research Center, Lausanne, Switzerland. large part of that research was limited to vitamins $\mathrm{C}$ and E (Peake, Suzuki, \& Coombes, 2007; Powers et al., 2004). Prolonged (4 weeks) supplementation with a combination of vitamin $\mathrm{C}$ and vitamin $\mathrm{E}$ attenuated the increase in $\mathrm{F}_{2}$-isoprostanes (a marker of lipid peroxidation) and was associated with a lower plasma interleukin-6 (IL-6) and cortisol response to prolonged exercise (Fischer et al., 2004). Furthermore, Davison and Gleeson (2007) demonstrated that acute vitamin $\mathrm{C}$ supplementation is associated with a reduction in the magnitude of exercise-induced neutrophil-function depression. However, to date, evidence to show that antioxidant supplementation can improve exercise performance and delay fatigue is still limited (Davis, Carlstedt, Chen, Carmichael, \& Murphy, 2010; McKenna et al., 2006; Medved et al., 2004).

There has been growing interest in recent research in the potential beneficial effects of cocoa because of the potent antioxidant properties of its constituent polyphenols. In two studies, when a high-phenolic-content antioxidant beverage (Morillas-Ruiz et al., 2005) or a polyphenol-containing sports drink (Morillas-Ruiz, Villegas Garcia, Lopez, Vidal-Guevara, \& Zafrilla, 2006) was consumed shortly before 15 min of submaximal aerobic exercise, the magnitude of exercise-induced oxidative stress was significantly reduced. Furthermore, short-term consumption of black currant extract, abundant in polyphenols, reduced exercise-induced oxidative stress and inflammatory responses (lipopolysaccharide inflamma- 
tory responses) to 30 min of rowing (Lyall et al., 2009), and green tea extract consumed acutely has been shown to stimulate lipid catabolism and increase fat oxidation after 30 min of cycling (Venables, Hulston, Cox, \& Jeukendrup, 2008). More recently, 7 days supplementation with quercetin, a natural polyphenol flavonoid, was reported to increase endurance capacity in untrained participants, possibly via increased mitochondrial biogenesis (Davis et al., 2010). Dark chocolate is one of the richest dietary sources of antioxidant polyphenols. Cocoa polyphenols, most notably the monomers catechin and epicatechin, can exist in both lipid- and water-based environments (amphipathic), meaning they can spare both lipophilic and hydrophilic vitamins. Studies have shown beneficial effects of chronic cocoa or dark chocolate consumption (Cooper, Donovan, Waterhouse, \& Williamson, 2008) in healthy participants (usually $\sim 100 \mathrm{~g}$ of dark chocolate per day for 2 weeks or more) on arterial and endothelial function (Vlachopoulos et al., 2005), resting blood pressure and insulin sensitivity (Grassi, Lippi, Necozione, Desideri, \& Ferri, 2005), or cholesterol profile (increased high-density lipoprotein [HDL] concentration; Mursu et al., 2004). However, there have been few studies investigating the potential of cocoa-containing foods to modulate exercise-induced oxidative stress and performance. Dark chocolate also contains caffeine and theobromine, which may also have potential ergogenic effects. Caffeine ingestion has been shown to increase fatty-acid mobilization from stores and spare glycogen while also stimulating the central nervous system and increasing muscle excitability, resulting in enhanced performance (Burke, 2008). Theobromine may also increase free-fattyacid mobilization, although its effects during exercise are unclear (Eteng \& Ettarh, 2000).

There is limited information on the effects of ingesting dark chocolate, rich in cocoa polyphenols, on oxidative stress and immunoendocrine responses after prolonged ( $>1.5 \mathrm{hr}$ duration) exercise and how this relates to exercise performance. Therefore, the aims of the current study were to examine the effects of a 2-week period of regular dark chocolate consumption on the responses of selected plasma markers of oxidative stress, hormones, and cytokines to a single bout of prolonged exhaustive exercise.

\section{Methods}

\section{Participants}

After we received university ethical committee approval, 20 healthy men (age $22 \pm 4$ years, body mass $74.6 \pm 8 \mathrm{~kg}$, maximal oxygen uptake $\left[\mathrm{VO}_{2 \max }\right] 53.1 \pm 7.0 \mathrm{ml} \cdot \mathrm{kg}^{-1}$. min $^{-1}$, power output at $\mathrm{VO}_{2 \max } 300 \pm 30 \mathrm{~W} ; M \pm S D$ ) participated in the study. They were all familiar with cycling and actively engaged in regular physical activity for a minimum of $2 \mathrm{hr}$, three times per week, as determined by a physical activity and health questionnaire. They were informed of the experimental procedures (written and verbally) before signing consent forms. Participants meeting one or more of the following criteria were excluded from the study: smoking, regular consumption of dark chocolate or similar high-polyphenol products or vitamin supplements, any sports supplements, medication, and alcohol. All participants completed four exercise bouts: two preliminary trials $\left(\mathrm{VO}_{2 \mathrm{max}}\right.$ determination and familiarization) and two main trials. Trials were separated by 1 week, and there was a 2-week washout period between the main trials.

\section{Design and Protocol}

Preliminary Measurements. Participants completed a continuous incremental exercise test to volitional exhaustion on an electronically braked cycle ergometer (Lode Excalibur, Holland). After a 3-min warm-up at $95 \mathrm{~W}$ they cycled with $35-\mathrm{W}$ increments every $3 \mathrm{~min}$ until volitional exhaustion. Expired-gas samples were collected in Douglas bags during the final minute of each stage. Heart rate (Polar A1, Polar Electro, Kempele, Finland) and rating of perceived exertion (Borg scale) were collected during this period. The expired gas was analyzed by an oxygen-carbon dioxide analyzer (Servomex 1400, Crowbridge, UK), and volume was measured by a dry gas meter (Harvard Apparatus, Edenbridge, UK) to determine ventilation, oxygen uptake, and carbon dioxide production. From the $\mathrm{VO}_{2}-$ work rate relationship, the work rates equivalent to $60 \%$ and $90 \% \mathrm{VO}_{2 \max }$ were interpolated. On a second occasion participants completed a familiarization ride. The purpose of this was to familiarize them with the exercise protocol and to check that the correct relative intensity exercise was being performed. Participants cycled for $1.5 \mathrm{hr}$ at a work rate equivalent to $60 \% \mathrm{VO}_{2 \max }$, and every $10 \mathrm{~min}$ the exercise intensity was increased to $90 \% \mathrm{VO}_{2 \max }$ for $30 \mathrm{~s}$. Expired-gas samples were collected over a 1-min period into Douglas bags after $10 \mathrm{~min}$ and $30 \mathrm{~min}$ of exercise and then every $30 \mathrm{~min}$ thereafter; heart rate and rating of perceived exertion were measured every $15 \mathrm{~min}$.

Main Trials. For the main trials, participants exercised under two different conditions-a DC (dark chocolate) trial or CON (control cocoa liquor-free chocolate) trial-in a single-blind, randomized, and counterbalanced design. They arrived at the laboratory at 9:30 a.m. on the days of the main trials after an overnight fast ( $>10 \mathrm{hr}$ ) followed by a breakfast at 8 a.m. that had consisted of chocolate ( $40 \mathrm{~g}$ DC or $30.4 \mathrm{~g}$ isocaloric CON) and $500 \mathrm{ml}$ water only. On arrival, participants were asked to empty their bladder, after which body mass was measured in minimal clothing. The exercise bouts began at 10 a.m. Water $(2.5 \mathrm{ml} / \mathrm{kg}$ body mass) was consumed at the onset, every $15 \mathrm{~min}$ during, and on completion of the exercise bout. Exercise consisted of steady-state cycling at $60 \%$ $\mathrm{VO}_{2 \max }$ for $1.5 \mathrm{hr}$; every $10 \mathrm{~min}$ the exercise intensity was increased to $90 \% \mathrm{VO}_{2 \max }$ for $30 \mathrm{~s}$. The exercise protocol was chosen to simulate a race situation with occasional bursts of higher intensity work while still having a standardized exercise protocol. It also served to familiarize the subjects with the effort required to exercise at $90 \% \mathrm{VO}_{2 \max }$ before they performed the ride 
to exhaustion at the end of the trial. At the end of the $1.5 \mathrm{hr}$ of exercise, subjects were given a 5-min break, immediately followed by a time-to-exhaustion trial (at $\left.90 \% \mathrm{VO}_{2 \max }\right)$. They were instructed to maintain a pedal cadence of more than $50 \mathrm{rpm}$ while cycling, to remain seated at all times, and to attempt to cycle for as long as possible. No external encouragement was given during the trial, and no information about elapsed time was given during the ride to exhaustion. Expired gas was collected into Douglas bags (1-min sample) during the 25 th, 55th, and 75th minutes of exercise, for analysis of $\mathrm{VO}_{2}$ and respiratory-exchange ratio (RER). Heart rate and rating of perceived exertion were recorded after $15 \mathrm{~min}$ of exercise and every 10 min thereafter. Heart rate alone was recorded unobtrusively every $5 \mathrm{~min}$ during the ride to exhaustion. After completion of the exhaustion trial, participants were weighed again.

Venous blood samples were taken at rest immediately before exercise (Pre-Ex), immediately after completing the 1.5-hr exercise bout (Post-Ex), immediately after completing an exercise bout to exhaustion (Post-Exh), and after $1 \mathrm{hr}$ of resting recovery ( $1 \mathrm{hr}$ Post-Exh). On each occasion $25 \mathrm{ml}$ blood was obtained from an antecubital vein with a 21-g butterfly needle and syringe. Blood was then dispensed into five Vacutainer tubes (Becton Dickinson, Oxford, UK), four $\mathrm{K}_{3}$ EDTA tubes, and one heparin tube.

Participants completed a food diary for the $48 \mathrm{hr}$ before the first trial (familiarization) and were required to follow the same diet during the $48 \mathrm{hr}$ before each main trial. They were required to abstain from alcohol, caffeine, polyphenol-containing products (other than the prescribed chocolate), and heavy exercise for $48 \mathrm{hr}$ before each trial and to have a rest day on the day immediately before each trial. It was also stipulated that participants should not take any mineral or vitamin supplement or any other antioxidant supplements during and for the 4 weeks before the study. They were provided with a food-exclusion list to ensure that they avoided highpolyphenol- and -caffeine-containing foods for the 48 $\mathrm{hr}$ before each main trial.

\section{Treatments}

Participants consumed the total daily amount of prescribed chocolate ( $80 \mathrm{~g}$ for DC, $56.8 \mathrm{~g}$ for CON) in two equal portions with their breakfast and evening meals every day for 2 weeks. They also consumed a portion of the same chocolate on the day of the main trials. To prevent changes in daily energy intake, participants were asked to replace their normal snacks (e.g., cookies, candy) or desserts with the chocolate but not to reduce their intake of fruit and vegetables.

The dark chocolate was $40.0 \mathrm{~g}$ Nestlé Noir ${ }^{\mathrm{TM}} 70 \%$ chocolate containing cocoa liquor, sugar, cocoa butter, milk fat, lecithin, and vanilla. The control chocolate $(30.4$ $\mathrm{g}$, which was $71 \%$ of the mass of the DC) was matched in terms of fat (18\%) and carbohydrate $(77 \%)$ content and total energy (2.1 MJ) and contained all the same ingredients except the cocoa liquor $(0 \%)$. (See Table 1 for more detailed composition.)
Table 1 Chocolate Composition

\begin{tabular}{lccc}
\hline & $\begin{array}{c}\text { DC } \\
\text { (absolute } \\
\text { amount } \\
\text { per } \mathbf{4 0 ~ g )}\end{array}$ & $\begin{array}{c}\text { CON } \\
\text { (absolute } \\
\text { amount } \\
\text { per } \mathbf{4 0 ~ g )}\end{array}$ & $\begin{array}{c}\text { CON } \\
\text { (absolute } \\
\text { amount per } \\
\mathbf{3 0 . 4} \mathbf{~ g ) ~}\end{array}$ \\
\hline Ash (g) & 0.84 & 0.0 & 0.0 \\
Protein (g) & 2.84 & 0.0 & 0.0 \\
Fat (OICC; g) & 17.4 & 25.1 & 17.8 \\
Fiber (g) & 4.3 & $<0.2$ & $<0.2$ \\
Energy (kJ) & 932 & 1,182 & 839 \\
Sucrose (g) & 10.3 & 14.6 & 10.4 \\
Caffeine (mg) & 41.6 & 9.6 & 6.8 \\
Theobromine (g) & 267 & 6.4 & 4.5 \\
Polyphenols (mg) & & & \\
catechin & 15.6 & 0 & 0 \\
epicatechin & 38.7 & 0 & 0 \\
Dimer B2 & 23.4 & 0 & 0 \\
Dimer B5 & 2.9 & 0 & 0 \\
Trimer C & 13.9 & 0 & 0 \\
Tetramer D & 4.2 & 0 & 0 \\
\hline
\end{tabular}

Note. $\mathrm{DC}=$ dark chocolate $\mathrm{CON}=$ control.

\section{Blood Analysis}

$\mathrm{K}_{3}$ EDTA blood was used for hematological analysis including hemoglobin, hematocrit, and total and differential leukocyte counts using an automated hematology analyzer $\left(\mathrm{A}^{\mathrm{C}} \cdot \mathrm{T}\right.$ 5diff analyzer, Beckman Coulter, UK). Plasma volume changes were calculated according to Dill and Costill (1974). The remaining $\mathrm{K}_{3}$ EDTA and heparinized whole blood was spun at $1,500 \mathrm{~g}$ for 10 min in a refrigerated centrifuge at $4{ }^{\circ} \mathrm{C}$ within $10 \mathrm{~min}$ of sampling. The plasma obtained was immediately stored at $-80{ }^{\circ} \mathrm{C}$ until analysis. $\mathrm{K}_{3}$ EDTA plasma was used to determine changes in the plasma concentrations of selected metabolites, hormones, cytokines, and markers of oxidative stress. Heparinized plasma was used for the analysis of triglycerides, vitamin $\mathrm{C}$, uric acid, and total antioxidant capacity.

Plasma Antioxidants. Plasma Trolox-equivalent antioxidant capacity (TEAC) was determined using an automated analyzer (Cobas-Mira Plus, Roche, Basle, Switzerland) and a commercially available kit (Randox, County Antrim, UK) for measuring the capacity of plasma to scavenge the 2,2'-azinobis-(3-ethylbenzothiazoline6-sulphonic acid) radical cation. Trolox was used as the standard, so this measure of total antioxidant status was expressed in Trolox-equivalent antioxidant units (mM). Plasma vitamin C concentration was determined according to Liu, Chin, Kiser, and Bigler (1982) using a specific spectrophotometric ascorbate oxidase (E 1.10.3.3) assay. Plasma uric acid concentration was determined according to a spectrophotometric method using a commercially available kit (Randox, County Antrim, UK). 
Plasma Markers of Oxidative Stress. Plasma free $\mathrm{F}_{2}$-isoprostane concentration and the plasma concentrations of oxidized low-density lipids (LDLs) were determined using commercially available ELISA kits according to the manufacturer's instructions (Cayman Chemical Co., Ann Arbor, MI, and Mercodia AB, Uppsala, Sweden, respectively).

Plasma Hormone and Cytokine Concentrations. Commercially available ELISA kits were used to determine the concentrations of cortisol (DRG Diagnostics, Marburg/Lahn, Germany), adrenocorticotropic hormone (Biomercia, Irvine, CA), insulin (ultrasensitive kit, DRG Diagnostics), glucagon (Cosmobio, Japan), IL-10 (highsensitivity kit, Diaclone, Besançon, France), IL-1ra (R\&D systems, Minneapolis, MN), and IL-6 (high-sensitivity kit, Diaclone).

Plasma Metabolite Concentrations. Plasma glucose concentration was determined on an automated analyzer (Cobas Mira Plus, Roche, Basel, Switzerland) using a colorimetric glucose oxidase PAP kit (Randox, County Antrim, UK). Plasma lactate concentration was determined on a spectrophotometer at $340 \mathrm{~nm}$ using a standard enzymatic assay with lactate dehydrogenase and nicotinamide adenine dinucleotide (Sigma, Poole, UK). Analysis of free fatty acids (FFAs) was performed using the Wako 999-75406 NEFA-C kit, and triglyceride analysis was performed using the triglyceride Infinity reagent kit (Alpha Laboratories, Eastleigh, UK).

\section{Data Analysis}

Data are presented as means and standard deviations. To compare the two different trials, DC and CON, a twoway repeated-measures ANOVA (Trial $\times$ Time) was used. Data that were not normally distributed were normalized with log transformation. Post hoc analysis was carried out, when appropriate, using paired-samples $t$ tests with the Holm-Bonferroni correction. When the two-way ANOVA showed a significant Trial $\times$ Time interaction (indicating different temporal responses depending on trial), one-way repeated-measures ANOVA was also used to determine the temporal response in each trial independently. The Greenhouse-Geisser correction was applied to all ANOVA $p$ values.

\section{Results}

The effects of DC on the physiological demands of exercise are presented in Table 2 . There were no significant differences between trials in overall exercise intensity during the steady-state exercise. Mean heart rates were similar between the two conditions, as were mean ratings of perceived exertion. RER did not differ significantly between trials $(p=.08)$. Times to exhaustion at $90 \%$ $\mathrm{VO}_{2 \max }$ were $398 \pm 204$ and $374 \pm 194 \mathrm{~s}$ for the DC and CON trials, respectively. There was no significant difference between treatments.

\section{Markers of Antioxidant Capacity}

Plasma uric acid concentration increased Post-Exh and $1 \mathrm{hr}$ Post-Exh compared with Preex in both trials (main effect of time, $p<.001)$. Vitamin $\mathrm{C}$ increased with time in both trials (main effect of time, $p<.001$ ). Total antioxidant status was higher Post-Exh than Pre-Ex (main effect of time, $p<.001$ ). These temporal responses were not significantly influenced by DC supplementation (Table 3 ).

\section{Markers of Oxidative Stress}

There was a significant main Trial $\times$ Time interaction effect $(p=.045)$ and main effect of time $(p<.01)$ and trial $(p<.001)$ for plasma free $\mathrm{F}_{2}$-isoprostane concentra-

Table 2 Heart Rate, Rating of Perceived Exertion, Percent of Maximal Oxygen Uptake, and Respiratory-Exchange Ratio During Exercise, M (SD)

\begin{tabular}{|c|c|c|c|c|}
\hline & $25 \mathrm{~min}$ & $55 \mathrm{~min}$ & $75 \mathrm{~min}$ & $\begin{array}{l}\text { Main-effects } p \text { values, trial; } \\
\text { time; Trial } \times \text { Time }^{\mathrm{a}}\end{array}$ \\
\hline Heart rate (beats/min) & & & & $>.1 ;<.001 ;>.1$ \\
\hline $\begin{array}{l}\text { dark chocolate trial } \\
\text { control trial }\end{array}$ & $\begin{array}{l}144(11) \\
145(10)\end{array}$ & $\begin{array}{l}152(13) \\
149(12)\end{array}$ & $\begin{array}{l}155(12) \\
152(10)\end{array}$ & \\
\hline Rating of perceived exertion & & & & $>.1 ;<.001 ;>.1$ \\
\hline $\begin{array}{l}\text { dark chocolate trial } \\
\text { control trial }\end{array}$ & $\begin{array}{l}11(1) \\
10(1)\end{array}$ & $\begin{array}{l}12(1) \\
12(1)\end{array}$ & $\begin{array}{l}12(1) \\
12(1)\end{array}$ & \\
\hline $\begin{array}{l}\text { Percent of maximal oxygen } \\
\text { uptake }\end{array}$ & & & & $>.1 ;<.001 ;>.1$ \\
\hline $\begin{array}{l}\text { dark chocolate trial } \\
\text { control trial }\end{array}$ & $\begin{array}{l}62.5(4.1) \\
61.5(6.3)\end{array}$ & $\begin{array}{l}64.5(4.1) \\
63.2(6.4)\end{array}$ & $\begin{array}{l}65.0(4.9) \\
64.6(6.8)\end{array}$ & \\
\hline Respiratory-exchange ratio & & & & $.08 ;<.001 ;>.1$ \\
\hline $\begin{array}{l}\text { dark chocolate trial } \\
\text { control trial }\end{array}$ & $\begin{array}{l}0.90(0.05) \\
0.92(0.03)\end{array}$ & $\begin{array}{l}0.88(0.04) \\
0.90(0.04)\end{array}$ & $\begin{array}{l}0.87(0.04) \\
0.90(0.03)\end{array}$ & \\
\hline
\end{tabular}

aResults from two-way ANOVA. 
tion. Values increased Post-Exh in both CON $(p<.001)$ and DC $(p<.001)$ but were significantly lower in DC at Post-Exh $(p<.001)$ and 1 hr Post-Exh $(p<.05)$ than in CON (Figure 1). There was a significant main Trial $\times$ Time interaction effect $(p=.027)$ and main effect of time $(p<.001)$ and trial $(p=.001)$ for plasma oxidized LDLs (Figure 2). Values were significantly lower in DC at PreEx, Post-Ex, and Post-Exh (all $p<.001)$ than in CON.

\section{Plasma Hormones}

Plasma insulin concentration decreased Post-Ex (main effect of time, $p<.001$ ), plasma glucagon increased Post-Ex (main effect of time, $p<.001$ ), and adrenocorticotropic hormone concentration increased Post-Ex and Post-Exh (main effect of time, $p<.001$ ) compared with
Pre-Ex. The overall temporal responses on these values were the same between trials (Table 4). Plasma cortisol concentration was not significantly affected by exercise or by trial (Table 4).

\section{Plasma Metabolites}

Plasma glucose concentration decreased at $1 \mathrm{hr}$ Post-Exh compared with Pre-Ex (main effect of time, $p<.001$ ), and plasma lactate concentration increased Post-Ex and Post-Exh (main effect of time, $p<.001$ ). The temporal responses were not different between trials (Table 5). Plasma FFA concentration increased Post-Ex and PostExh compared with Pre-Ex in both trials. There was also a significant main effect of trial $(p=.038)$, with higher FFA levels in DC than in CON (Figure 3). Plasma triglyc-

Table 3 Markers of Antioxidant Status Before and After Exercise, M (SD)

\begin{tabular}{lccccc}
\hline & Pre-Ex & Post-Ex & Post-Exh & 1 hr Post-Exh & $\begin{array}{c}\text { Main-effects } \boldsymbol{p} \text { values, } \\
\text { trial; time; Trial } \times \text { Time }\end{array}$ \\
\hline Vitamin $\mathrm{C}(\mu \mathrm{M})$ & & & & & $>.1 ;<.001 ;>.1$ \\
$\quad$ dark chocolate trial & $54.8(5.0)$ & $58.3(5.7)$ & $62.9(5.6)$ & $61.9(5.9)$ & \\
$\quad$ control trial & $54.2(6.1)$ & $56.7(6.8)$ & $61.8(6.2)$ & $62.3(5.6)$ & $>.1 ;<.001 ;>.1$ \\
$\begin{array}{l}\text { Uric acid }(\mu \mathrm{M}) \\
\quad \text { dark chocolate trial }\end{array}$ & $352(63)$ & $375(73)$ & $417(110)$ & $424(83)$ & \\
$\quad$ control trial & $345(55)$ & $351(53)$ & $407(80)$ & $400(72)$ & $.07 ;<.001 ;>.1$ \\
$\quad$ & & & & \\
$\quad$ Total antioxidant status $(\mathrm{mM})$ & & & & \\
$\quad$ dark chocolate trial & $1.45(0.09)$ & $1.54(0.14)$ & $1.62(0.15)$ & $1.50(0.11)$ & \\
$\quad$ control trial & $1.35(0.30)$ & $1.48(0.06)$ & $1.58(0.20)$ & $1.45(0.14)$ & \\
\hline
\end{tabular}

Note. Ex = exercise; Exh = exhaustion.

${ }^{a}$ Results from two-way ANOVA.

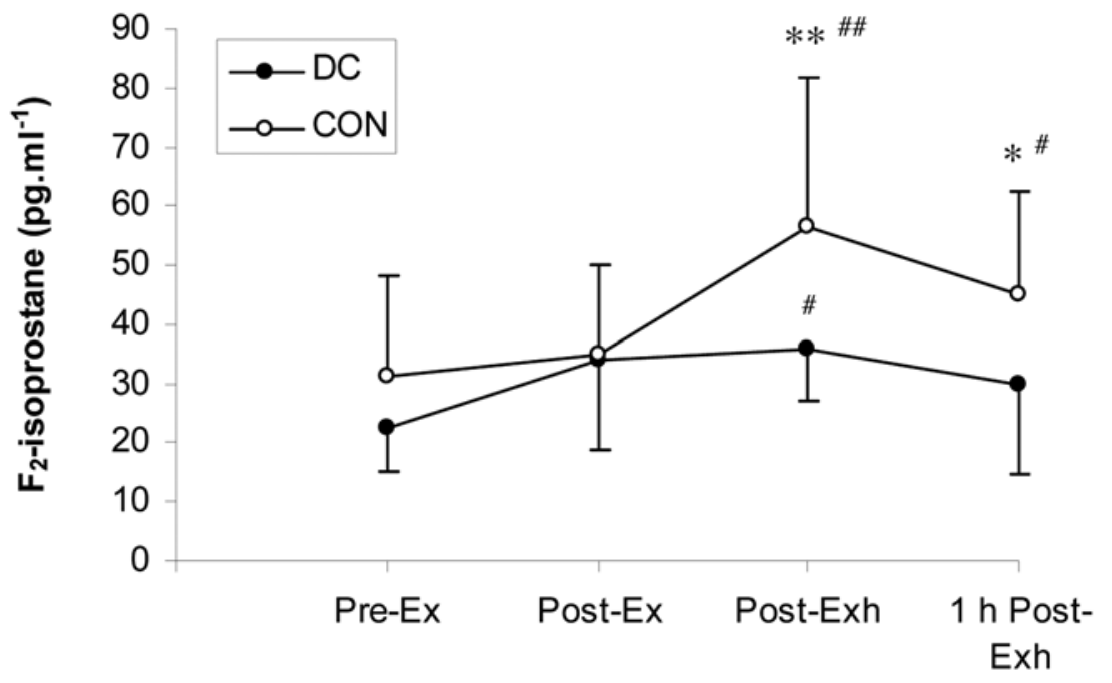

Figure $1-\mathrm{F}_{2}$-isoprostane levels before and after exercise, $M(S D) . \mathrm{DC}=$ dark chocolate; $\mathrm{CON}=\mathrm{control}$; Pre-Ex = preexercise; Post-Ex $=$ postexercise; Post-Exh $=$ postexhaustion. $*$ Significantly different from CON,$p<.05$. **Significantly different from CON, $p<.001$. \#Significantly higher than resting values within trial, $p<.05$. \#\#Significantly higher than resting values within trial, $p<.001$. 


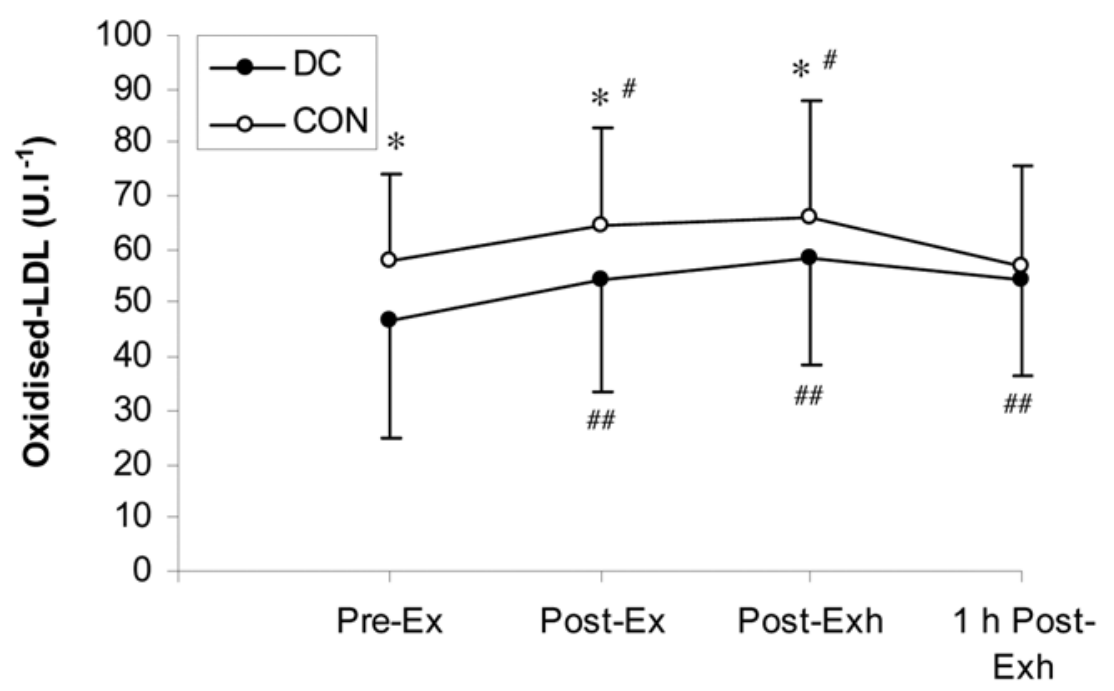

Figure 2 - Oxidized low-density-lipid (LDL) levels before and after exercise, $M(S D)$. DC = dark chocolate; CON = control; Pre-Ex = preexercise; Post-Ex = postexercise; Post-Exh = postexhaustion. $*$ Significantly different from CON, $p<.001$. \#Significantly higher than resting values within trial, $p<.05$. \#\#Significantly higher than resting values within trial, $p<.001$.

Table 4 Circulating Hormones Before and After Exercise, M (SD)

\begin{tabular}{|c|c|c|c|c|c|}
\hline & Pre-Ex & Post-Ex & Post-Exh & $1 \mathrm{hr}$ Post-Exh & $\begin{array}{c}\text { Main-effects } p \text { values, trial } \\
\text { time; Trial } \times \text { Time }^{\mathrm{a}}\end{array}$ \\
\hline Insulin (mU/L) & & & & & $>.1 ;<.001 ; .071$ \\
\hline dark chocolate trial & $7.3(4.0)$ & $4.3(4.2)$ & $3.6(4.3)$ & $1.8(1.3)$ & \\
\hline control trial & $4.9(3.5)$ & $2.6(2.2)$ & $3.4(3.1)$ & $1.6(1.2)$ & \\
\hline Glucagon (pg/ml) & & & & & $>.1 ;<.001 ;>.1$ \\
\hline $\begin{array}{l}\text { dark chocolate trial } \\
\text { control trial }\end{array}$ & $\begin{array}{l}337(190) \\
356(261)\end{array}$ & $\begin{array}{l}411(249) \\
402(200)\end{array}$ & $\begin{array}{l}415(237) \\
432(277)\end{array}$ & $\begin{array}{l}352(207) \\
359(206)\end{array}$ & \\
\hline $\begin{array}{l}\text { Adrenocorticotropic } \\
\text { hormone }(\mathrm{pg} / \mathrm{ml})\end{array}$ & & & & & $>.1 ;<.001 ;>.1$ \\
\hline $\begin{array}{l}\text { dark chocolate trial } \\
\text { control trial }\end{array}$ & $\begin{array}{l}34.1(21.2) \\
35.4(27.8)\end{array}$ & $\begin{array}{l}62.0(41.8) \\
60.9(37.5)\end{array}$ & $\begin{array}{l}88.4(59.4) \\
88.0(44.6)\end{array}$ & $\begin{array}{l}22.9(15.4) \\
19.4(11.3)\end{array}$ & \\
\hline Cortisol (nM) & & & & & $>.1 ; .094 ;>.1$ \\
\hline $\begin{array}{l}\text { dark chocolate trial } \\
\text { control trial }\end{array}$ & $\begin{array}{l}365(103) \\
370(94)\end{array}$ & $\begin{array}{l}377(136) \\
406(123)\end{array}$ & $\begin{array}{l}391(137) \\
422(109)\end{array}$ & $\begin{array}{l}359(109) \\
351(94)\end{array}$ & \\
\hline
\end{tabular}

Note. Ex = exercise; Exh = exhaustion.

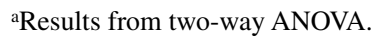

erides were higher at Post-Ex and Post-Exh than Pre-Ex on both trials (main effect of time, $p<.001$ ) but did not differ significantly between trials (Figure 4).

\section{Circulating Leukocytes and Cytokines}

Circulating leukocyte count $(p=.001)$, neutrophil count $(p<.001)$, plasma IL-6 concentration $(p<.001)$, and IL-10 concentration $(p<.001)$ all increased after exercise and remained elevated throughout the exercise protocol (Table 6). However, these temporal patterns did not differ between trials. Plasma IL-1ra (Table 6) was elevated at Post-Exh and $1 \mathrm{hr}$ Post-Exh compared with Pre-Ex (main effect of time, $p<.001$ ), with no difference between trials.

\section{Discussion}

The main findings of the study were that chronic consumption of DC daily for 2 weeks before an acute bout of prolonged exhaustive exercise resulted in lower resting and postexercise plasma levels of the oxidative stress markers $\mathrm{F}_{2}$-isoprostanes and oxidized LDL but had no effect on cytokine responses. Dark chocolate ingestion was associated with greater rises in plasma FFA during exercise and a tendency for a lower RER (suggesting a higher contribution of fat oxidation to energy expenditure). However, regular consumption of DC had no significant effect on time to fatigue compared with isocarbohydrate-fat control. 
Table 5 Circulating Glucose and Lactate Before and After Exercise, $M(S D)$

\begin{tabular}{lccccc}
\hline & Pre-Ex & Post-Ex & Post-Exh & 1 hr Post-Exh & $\begin{array}{c}\text { Main-effects } \boldsymbol{p} \text { values, trial; } \\
\text { time; Trial } \times \text { Time }\end{array}$ \\
\hline Glucose $(\mathrm{mM})$ & & & & & $>.1 ;<.001 ;>.1$ \\
$\quad$ dark chocolate trial & $4.97(0.50)$ & $4.82(0.78)$ & $4.85(0.90)$ & $4.53(0.78)$ & \\
$\quad$ control trial & $5.05(0.40)$ & $4.84(0.52)$ & $5.06(0.92)$ & $4.58(0.44)$ & \\
Lactate $(\mathrm{mM})$ & & & & & $>.1 ;<.001 ;>.1$ \\
$\quad$ dark chocolate trial & $1.2(0.3)$ & $3.1(1.2)$ & $8.2(1.7)$ & $1.2(0.4)$ & \\
$\quad$ control trial & $1.2(0.2)$ & $3.3(1.1)$ & $8.1(1.8)$ & $1.2(0.3)$ & \\
\hline
\end{tabular}

Note . Ex $=$ exercise Exh $=$ exhaustion.

aResults from two-way ANOVA.

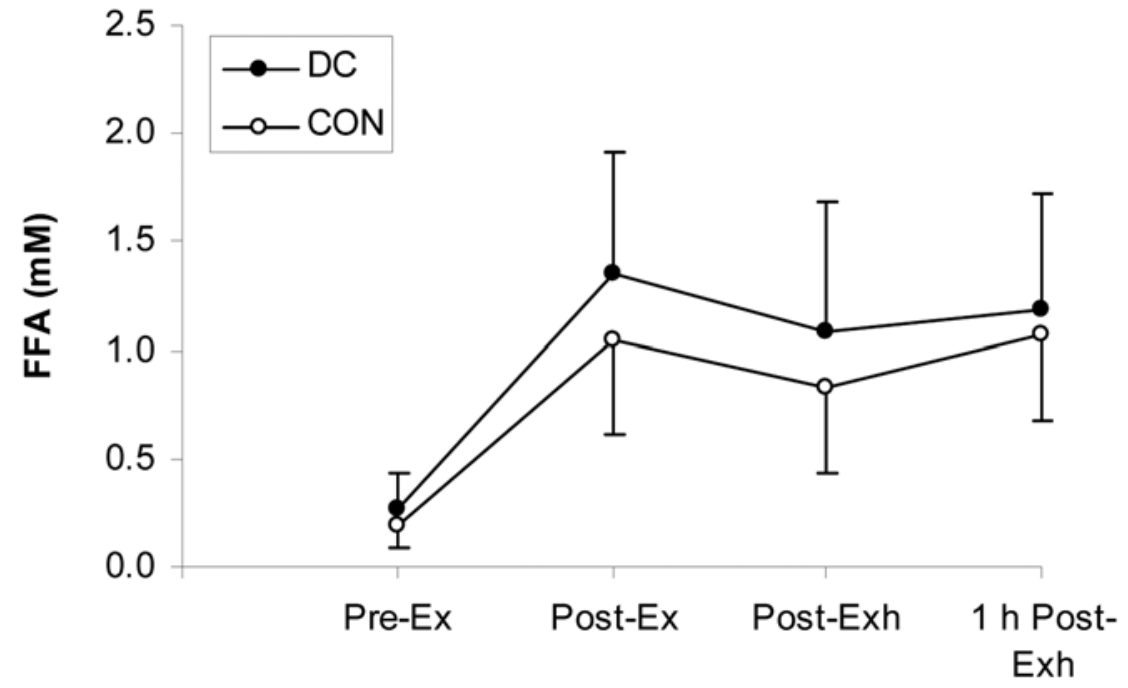

Figure 3 - Free-fatty-acid (FFA) concentration before and after exercise, $M(S D)$. Significant main effect of trial, $p=.038$. DC $=$ dark chocolate; $\mathrm{CON}=$ control; Pre-Ex = preexercise $;$ Post-Ex = postexercise $;$ Post-Exh = postexhaustion.

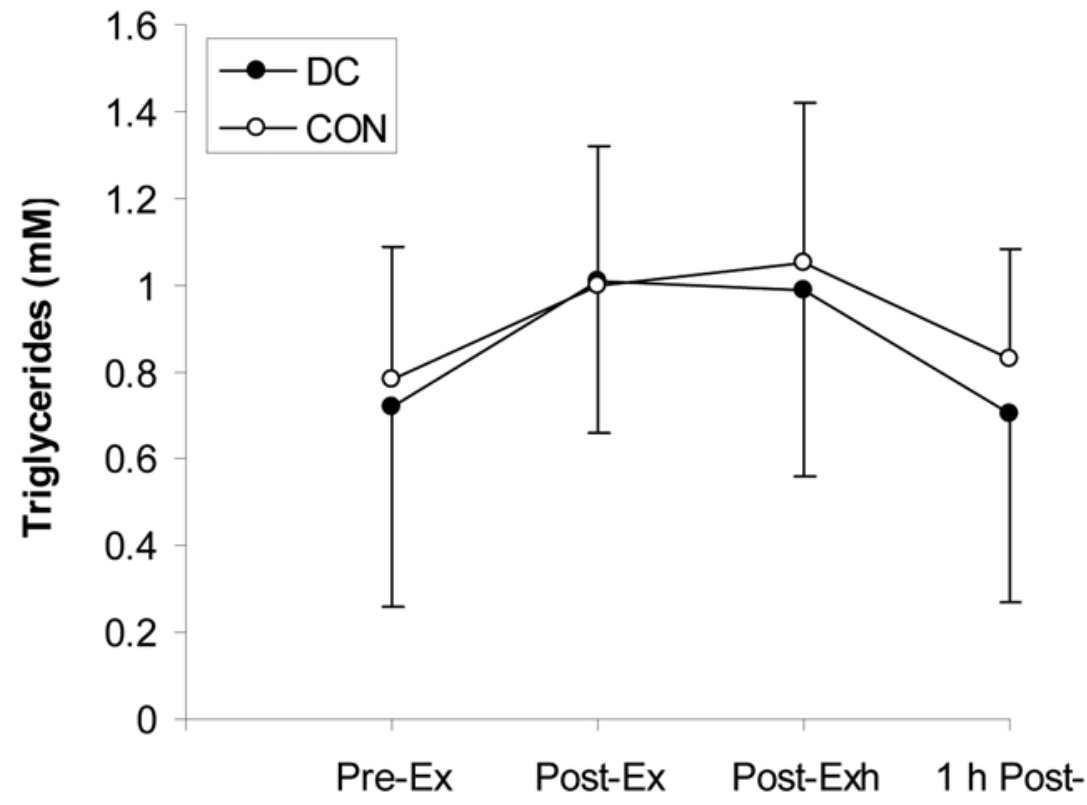

Exh

Figure 4 - Triglyceride concentration before and after exercise, $M(S D)$. DC = dark chocolate; $\mathrm{CON}=$ control; Pre-Ex = preexercise; Post-Ex = postexercise; Post-Exh = postexhaustion. 
Table 6 Circulating Leukocyte Counts and Plasma Cytokines Before and After Exercise, M (SD)

\begin{tabular}{|c|c|c|c|c|c|}
\hline & Pre-Ex & Post-Ex & Post-Exh & $1 \mathrm{hr}$ Post-Exh & $\begin{array}{c}\text { Main-effects } p \text { values, trial; } \\
\text { time; Trial } \times \text { Time }^{\mathrm{a}}\end{array}$ \\
\hline Leukocyte count $\left(\times 10^{9} / \mathrm{L}\right)$ & & & & & $>.1 ;<.001 ;>.1$ \\
\hline $\begin{array}{l}\text { dark chocolate trial } \\
\text { control trial }\end{array}$ & $\begin{array}{l}5.8(1.6) \\
5.5(1.6)\end{array}$ & $\begin{array}{l}10.9(3.9) \\
10.3(3.7)\end{array}$ & $\begin{array}{l}13.8(5.0) \\
13.2(4.3)\end{array}$ & $\begin{array}{l}11.4(4.4) \\
11.3(3.4)\end{array}$ & \\
\hline Neutrophil count $\left(\times 10^{9} / \mathrm{L}\right)$ & & & & & $>.1 ;<.001 ;>.1$ \\
\hline $\begin{array}{l}\text { dark chocolate trial } \\
\text { control trial }\end{array}$ & $\begin{array}{l}2.8(1.2) \\
2.7(0.9)\end{array}$ & $\begin{array}{l}6.6(3.3) \\
6.3(2.7)\end{array}$ & $\begin{array}{l}8.3(4.1) \\
7.9(3.3)\end{array}$ & $\begin{array}{l}8.8(3.9) \\
8.8(3.0)\end{array}$ & \\
\hline $\begin{array}{l}\text { IL-6 }(\mathrm{pg} / \mathrm{ml}) \\
\text { dark chocolate trial } \\
\text { control trial }\end{array}$ & $\begin{array}{l}1.7(2.3) \\
1.8(2.2)\end{array}$ & $\begin{array}{l}3.0(2.1) \\
3.2(2.4)\end{array}$ & $\begin{array}{l}3.9(1.8) \\
4.2(2.7)\end{array}$ & $\begin{array}{l}2.7(2.2) \\
2.7(2.0)\end{array}$ & $>.1 ;<.001 ;>.1$ \\
\hline $\begin{array}{l}\text { IL-10 }(\mathrm{pg} / \mathrm{ml}) \\
\text { dark chocolate trial } \\
\text { control trial }\end{array}$ & $\begin{array}{l}1.9(1.7) \\
1.8(1.2)\end{array}$ & $\begin{array}{l}2.7(1.5) \\
2.3(1.2)\end{array}$ & $\begin{array}{l}2.8(1.9) \\
2.9(1.5)\end{array}$ & $\begin{array}{l}3.7(2.7) \\
2.5(1.9)\end{array}$ & $>.1 ; .031 ; .053$ \\
\hline $\begin{array}{l}\text { IL-1ra }(\mathrm{pg} / \mathrm{ml}) \\
\text { dark chocolate trial } \\
\text { control trial }\end{array}$ & $\begin{array}{l}320(180) \\
267(75)\end{array}$ & $\begin{array}{l}402(187) \\
348(115)\end{array}$ & $\begin{array}{l}502(220) \\
438(170)\end{array}$ & $\begin{array}{l}1067(895) \\
1081(845)\end{array}$ & $>.1 ;<.001 ;>.1$ \\
\hline
\end{tabular}

Note Ex $=$ exercise Exh $=$ exhaustion.

${ }^{a}$ Results from two-way ANOVA.

The current results show a blunting of the oxidativestress marker $\mathrm{F}_{2}$-isoprostane in response to prolonged exercise with DC consumption. $\mathrm{F}_{2}$-isoprostane is considered a reliable and sensitive marker of lipid peroxidation (Roberts \& Morrow, 2000). These findings are in line with those of Wiswedel et al. (2004), who observed a lower level of plasma $\mathrm{F}_{2}$-isoprostane after a high-flavanol (187 $\mathrm{mg}$ flavanols $/ 100 \mathrm{ml}$ ) cocoa drink than with a low-flavanol cocoa drink (14 mg flavanols $/ 100 \mathrm{ml})$. However, they observed no effect of exercise on oxidative stress, which was most likely because of the relatively short duration of the exercise bout (29 min). Furthermore, a lower $\mathrm{F}_{2}$-isoprostane response has been observed with vitamin $\mathrm{C}$ and $\mathrm{E}$ consumption after $3 \mathrm{hr}$ of knee-extensor exercise at $50 \%$ of maximal power output (Fischer et al., 2004) and after a 50-km ultramarathon (Mastaloudis, Morrow, Hopkins, Devaraj, \& Traber, 2004). In the current study, the reduced $\mathrm{F}_{2}$-isoprostane response with DC consumption was paralleled by lower levels of oxidized LDL. Decreased rates of ex vivo LDL oxidation have been shown after consumption at rest of flavanol-rich chocolate (Osakabe et al., 2001; Wan et al., 2001). Although these results indicate a chronic effect of DC on oxidative stress both at rest and in response to exercise, one cannot exclude a possible acute effect of the $40 \mathrm{~g}$ of DC ingested $2 \mathrm{hr}$ before exercise.

DC resulted in an increase in FFA concentration postexercise, indicating an increase in adipocyte lipolysis. These effects most likely occur via the inhibition of catechol O-methyltransferase, an enzyme that degrades noradrenaline, which may prolong adrenergic drive and increase lipolysis (Dulloo et al., 1999). Venables et al. (2008) demonstrated that three capsules of green tea (890 $\mathrm{mg}$ polyphenols and $366 \mathrm{mg}$ epigallocatechin gallate) ingested in the 24-hr period before $30 \mathrm{~min}$ of exercise at $60 \% \mathrm{VO}_{2 \max }$ resulted in higher levels of plasma FFA with a concomitant increase in fat oxidation. RER values measured during exercise tended to be lower with DC in the current study, suggesting an increase in fat oxidation to energy expenditure. However, because FFA concentration was only measured in the postexercise period, a direct comparison between these two parameters cannot be made. An increase in FFA mobilization during prolonged exercise after dark chocolate consumption could be viewed as beneficial to those who may be exercising as part of a weight-loss program, in addition to athletes attempting to conserve carbohydrate stores. It is worth noting that both caffeine and theobromine can independently promote lipolysis and increase FFA concentration (Durham, Miller, Lindeman, \& Lapachet, 1993). Furthermore, catechins are suggested to act synergistically with caffeine to enhance fat oxidation (Dulloo, Seydoux, Girardier, Chantre, \& Vandermander, 2000). Because the DC contained low levels of caffeine $(41.6 \mathrm{mg})$ and theobromine $(267 \mathrm{mg})$ that were ingested $2 \mathrm{hr}$ before exercise, it is not possible to determine whether caffeine, theobromine, or polyphenol content, either in isolation or in combination, was responsible for the effect on FFA.

Previous studies have shown enhanced antioxidant capacity after DC consumption (Rein et al., 2000; Serafini et al., 2003; Wang et al., 2000). Several components of plasma contribute to plasma TEAC. Albumin and uric acid are thought to account for two thirds of the plasma TEAC. Many proteins such as ceruloplasmin and transferrin and small antioxidant molecules such as nonprotein thiols and vitamins $\mathrm{C}$ and $\mathrm{E}$ account for the remainder of the plasma TEAC. Ingestion of polyphenolcontaining foods could raise the plasma polyphenol 
content, although this may not be enough to affect the TEAC value because of the overwhelming contribution of the other plasma components. However, ingestion of polyphenols or indeed other components in the chocolate may affect the TEAC through changes in the endogenous plasma components. This may explain the lack of significant difference in plasma antioxidant capacity between treatments observed in the current study. Furthermore, the physiological relevance of these tests in plasma is currently controversial (Sies, 2007).

There are currently limited data in human studies to suggest that antioxidant supplementation enhances exercise performance through preventing oxidative mechanisms and muscle fatigue (Powers et al., 2004). $\mathrm{N}$-acetylcysteine supplementation acutely $(<1 \mathrm{hr})$ before exercise and during exercise delayed time to fatigue by $\sim 24 \%$ at $91 \% \mathrm{VO}_{2 \max }$ after 45 min submaximal cycling at $71 \% \mathrm{VO}_{2 \max }$ (McKenna et al. 2006), and 7 days of quercetin supplementation increased $\mathrm{VO}_{2 \max }(\sim 3.9 \%)$ and cycling time $(\sim 13.2 \%)$ to fatigue at $75 \% \mathrm{VO}_{2 \max }$ in untrained participants (Davis et al., 2010). There was no significant effect of dietary DC intake on exercise performance in the current study. In fact, some evidence suggests that antioxidant supplementation may inhibit some of the exercise-induced cellular signaling that up-regulates adaptations in vascular tissue and skeletal muscle (Sen, 2001), which may limit exercise performance (Malm, Svensson, Ekblom, \& Sjodin, 1997; Peake et al., 2007).

Chronic daily ingestion of vitamin $\mathrm{C}$ or combined vitamin $\mathrm{C}$ and $\mathrm{E}$ supplements over several weeks have been shown to decrease the IL- 6 and cortisol responses to prolonged exercise (Fischer et al., 2004; Vassilakopoulos et al., 2003). However, Nieman et al. (2004) reported no effect of daily vitamin $\mathrm{E}$ supplements over 2 months on cortisol and IL-6 compared with placebo after a competitive triathlon event. Furthermore, Mastaloudis et al. (2004) found no effect of 6 weeks of vitamin C and E supplementation on IL-6 after a 50-km ultramarathon, despite preventing increases in plasma lipid peroxidation. In the current study chronic consumption of DC had no effect on plasma adrenocorticotropic hormone, cortisol, IL-6, or IL-1ra concentrations after prolonged exercise, and in line with Mastaloudis et al., this indicates that oxidative damage and the inflammatory response to exercise operate independently (Nieman et al., 2002).

Oxidative stress has been implicated in the depression of immune-cell function that typically occurs after prolonged exercise, the magnitude of which may be decreased with appropriate preexercise antioxidant supplementation (Davison \& Gleeson, 2006; Lee \& Wan, 2000; Robson, Bouic, \& Myburgh, 2003). However, there was no significant effect of DC consumption on circulating leukocyte or neutrophil numbers at rest or in response to exercise. Leukocytosis is influenced by both cortisol and some cytokines (IL-6), and because there was no effect of DC consumption on these responses in the current study, it is perhaps not surprising that there was no effect on neutrophil numbers. The finding of a reduction in oxidative-stress markers with DC with no effect on leukocytes also suggests that these effects are a result of a direct "antioxidant" effect and not via other indirect mechanisms occurring in blood.

In conclusion, the current study demonstrates that DC consumption daily for 2 weeks and $2 \mathrm{hr}$ before prolonged exercise has significant effects on oxidativestress markers and the temporal response of plasma FFA. However, there were no effects on the plasma concentration of measured hormones, cytokines, or circulating numbers of total leukocytes and neutrophils or on exercise performance.

\section{Acknowledgments}

The authors would like to acknowledge the expert help of Trent Stellingwerff for his knowledge of sport nutrition, the statistical assistance of Dominik Grathwohl and Shahram Emady-Azar, and Juliet Farrar and Maurice Beaumont for study coordination. We would also like to acknowledge Samuel Bize and Antoine Lévéques for the chocolate-bar molding and the Nestlé UK Quality Assurance Laboratory for the polyphenol and nutrient analyses, as well as Dr. Michael Atkinson (biostatistician), Corinne Yorston, and all the participating athletes for their invaluable help and participation.

\section{References}

Burke, L.M. (2008). Caffeine and sports performance. Applied Physiology, Nutrition, and Metabolism, 33, 1319-1334.

Cooper K.A., Donovan J.L., Waterhouse A.L., \& Williamson, G. (2008). Cocoa and health: A decade of research. British Journal of Nutrition, 99, 1-11.

Davies, K.J., Quintanilha, A.T., Brooks, G.A., \& Packer, L. (1982). Free radicals and tissue damage produced by exercise. Biochemical and Biophysical Research Communications, 31(107), 1198-1205.

Davis, J.M., Carlstedt, C.J., Chen, S., Carmichael, M.D., \& Murphy, E.A. (2010). The dietary flavonoid quercetin increases VO2max and endurance capacity. International Journal of Sport Nutrition and Exercise Metabolism, 20, $56-62$.

Davison, G., \& Gleeson, M. (2006). The effect of 2 weeks vitamin $\mathrm{C}$ supplementation on immunoendocrine responses to $2.5 \mathrm{~h}$ cycling exercise in man. European Journal of Applied Physiology, 97, 454-461.

Davison, G., \& Gleeson, M. (2007). The effects of acute vitamin C supplementation on cortisol, interleukin-6, and neutrophil responses to prolonged cycling exercise. European Journal of Sport Science, 7, 15-25.

Dill, D.B., \& Costill, D.L. (1974). Calculation of percentage changes in volumes of blood, plasma, and red cells in dehydration. Journal of Applied Physiology, 37, 247-248.

Dulloo, A.G., Duret, C., Rohrer, D., Girardier, L., Mensi, N., Fathi, M., ... Vandermander, J. (1999). Efficacy of a green tea extract rich in catechin polyphenols and caffeine in increasing 24-h energy expenditure and fat oxidation in humans. The American Journal of Clinical Nutrition, 70, 1040-1045. 
Dulloo, A.G., Seydoux, J., Girardier, L., Chantre, P., \& Vandermander, J. (2000). Green tea and thermogenesis: Interactions between catechin-polyphenols, caffeine and sympathetic activity. International Journal of Obesity and Related Metabolic Disorders, 24, 252-258.

Durham, T., Miller, W., Lindeman, A., \& Lapachet, R. (1993). Effects of theobromine ingestion on plasma fatty acids, glycogen, and exercise endurance in untrained rats. Research in Sports Medicine, 4, 205-210.

Eteng, M.U., \& Ettarh, R.R. (2000). Comparative effects of theobromine and cocoa extract on lipid profile in rats. Nutrition Research (New York, N.Y.), 20, 1513-1517.

Fischer, C.P., Hiscock, N.J., Penkowa, M., Basu, S., Vessby, B., Kallner, A., . . Pedersen, B.K. (2004). Supplementation with vitamins $C$ and $E$ inhibits the release of interleukin-6 from contracting human skeletal muscle. The Journal of Physiology, 558, 633-645.

Grassi, D., Lippi, C., Necozione, S., Desideri, G., \& Ferri, C. (2005). Short-term administration of dark chocolate is followed by a significant increase in insulin sensitivity and a decrease in blood pressure in healthy persons. The American Journal of Clinical Nutrition, 81, 611-614.

Jackson, M.J., Pyne, D., \& Palomero, J. (2007). The production of reactive oxygen and nitrogen species by skeletal muscle. Journal of Applied Physiology, 102, 1664-1670.

Lee, C.Y., \& Wan, M.F. (2000). Vitamin E supplementation improves cell-mediated immunity and oxidative stress of Asian men and women. The Journal of Nutrition, 130, 2932-2937.

Liu, T.Z., Chin, N., Kiser, M.D., \& Bigler, W.N. (1982). Specific spectrophotometry of ascorbic acid in serum or plasma by use of ascorbate oxidase. Clinical Chemistry, 28, 2225-2258.

Lyall, K.A., Hurst, S.M., Cooney, J., Jensen, D., Lo, K., Hurst, R.D., \& Stevenson, L.M. (2009). Short-term blackcurrant extract consumption modulates exercise-induced oxidative stress and lipopolysaccharide-stimulated inflammatory responses. American Journal of Physiology. Regulatory, Integrative and Comparative Physiology, 297, R70-R81.

Malm, C., Svensson, M., Ekblom, B., \& Sjodin, B. (1997). Effects of ubiquinone-10 supplementation and high intensity training on physical performance in humans. Acta Physiologica Scandinavica, 161, 379-384.

Mastaloudis, A., Morrow, J.D., Hopkins, D.W., Devaraj, S., \& Traber, M.G. (2004). Antioxidant supplementation prevents exercise-induced lipid peroxidation, but not inflammation, in ultramarathon runners. Free Radical Biology \& Medicine, 36, 1329-1341.

McKenna, M.J., Medved, I., Goodman, C.A., Brown, M.J., Bjorksten, A.R., Murphy, K.T., . . G Gong, X. (2006). $\mathrm{N}$-acetylcysteine attenuates the decline in muscle $\mathrm{Na}^{+}, \mathrm{K}^{+}-$ pump activity and delays fatigue during prolonged exercise in humans. The Journal of Physiology, 576, 279-288.

Medved, I., Brown, M.J., Bjorksten, A.R., Murphy, K.T., Petersen, A.C., Sostaric, S., . . McKenna, M.J. (2004). $\mathrm{N}$-acetylcysteine enhances muscle cysteine and glutathione availability and attenuates fatigue during prolonged exercise in endurance-trained individuals. Journal of Applied Physiology, 97, 1477-1485.
Morillas-Ruiz, J., Zafrilla, P., Almar, M., Cuevas, M.J., López, F.J., Abellan, P., . . . Gónzalez-Galleto, J. (2005). The effects of an antioxidant-supplemented beverage on exercise-induced oxidative stress: Results from a placebocontrolled double-blind study in cyclists. European Journal of Applied Physiology, 95(5-6), 543-549.

Morillas-Ruiz, J.M., Villegas Garcia, J.A., Lopez, F.J., VidalGuevara, M.L., \& Zafrilla, P. (2006). Effects of polyphenolic antioxidants on exercise-induced oxidative stress. Clinical Nutrition (Edinburgh, Lothian), 25, 444-453.

Mursu, J., Voutilainen, S., Nurmi, T., Rissanen, T.H., Virtanen, J.K., Kaikkonen, J., . . Salonen, J.T. (2004). Dark chocolate consumption increases HDL cholesterol concentration and chocolate fatty acids may inhibit lipid peroxidation in healthy humans. Free Radical Biology \& Medicine, 37, 1351-1359.

Nieman, D.C., Henson, D.A., McAnulty, S.R., McAnulty, L., Swick, N.S., Utter, A.C., . . . Morrow, J.D. (2002). Influence of vitamin $\mathrm{C}$ supplementation on oxidative and immune changes after an ultramarathon. Journal of Applied Physiology, 92, 1970-1977.

Nieman, D.C., Henson, D.A., McAnulty, S.R., McAnulty, L.S., Morrow, J.D., Ahmed, A., \& Heward, C.B. (2004). Vitamin $\mathrm{E}$ and immunity after the Kona Triathlon World Championship. Medicine and Science in Sports and Exercise, 36(8), 1328-1335.

Nikolaidis, M.G., \& Jamurtas, A.Z. (2009). Blood as a reactive species generator and redox status regulator during exercise. Archives of Biochemistry and Biophysics, 490, 77-84.

Osakabe, N., Baba, S., Yasuda, A., Iwamoto, T., Kamiyama, M., Takizawa, T., . . Kondo, K. (2001). Daily cocoa intake reduces the susceptibility of low-density lipoprotein to oxidation as demonstrated in healthy human volunteers. Free Radical Research, 34, 93-99.

Peake, J.M., Suzuki, K., \& Coombes, J.S. (2007). The influence of antioxidant supplementation on markers of inflammation and the relationship to oxidative stress after exercise. The Journal of Nutritional Biochemistry, 18, 357-371.

Powers, S.K., Deruisseau, K.C., Quindry, J., \& Hamilton, K.L. (2004). Dietary antioxidants and exercise. Journal of Sports Sciences, 22, 81-94.

Rein, D., Lotito, S., Holt, R.R., Keen, C.L., Schmitz H.H., \& Fraga, C.G. (2000). Epicatechin in human plasma: In vivo determination and effect of chocolate consumption on plasma oxidation status. Journal of Nutrition, $130(8$ Suppl.), 2109S-2114S.

Roberts, L.J., \& Morrow, J.D. (2000). Measurement of F2-isoprostanes as an index of oxidative stress in vivo. Free Radical Biology \& Medicine, 28, 505-513.

Robson, P.J., Bouic, P.J.D., \& Myburgh, K.H. (2003). Antioxidant supplementation enhances neutrophil oxidative burst in trained runners following prolonged exercise. International Journal of Sport Nutrition and Exercise Metabolism, 13, 369-381.

Sen, C.K. (2001). Antioxidant and redox regulation of cellular signaling: Introduction. Medicine and Science in Sports and Exercise, 33, 368-370.

Serafini, M., Bugianesi, R., Maiani, G., Valtuena, S., De Santis, S., \& Crozier, A. (2003). Plasma antioxidants from chocolate. Nature, 424, 1013. 
Sies, H. (2007). Total antioxidant capacity: Appraisal of a concept. Journal of Nutrition, 137, 1493-1495.

Vassilakopoulos, T., Karatza, M.H., Katsaounou, P., Kollintza, A., Zakynthinos, S., \& Roussos, C. (2003). Antioxidants attenuate the plasma cytokine response to exercise in humans. Journal of Applied Physiology, 94, 1025-1032.

Venables, M.C., Hulston, C.J., Cox, H.R., \& Jeukendrup, A.E. (2008). Green tea extract ingestion, fat oxidation, and glucose tolerance in healthy humans. The American Journal of Clinical Nutrition, 87, 778-784.

Vlachopoulos, C., Aznaouridis, K., Alexopoulos, N., Economou, E., Andreadou, I., \& Stefanadis, C. (2005). Effect of dark chocolate on arterial function in healthy individuals. American Journal of Hypertension, 18, 785-791.
Wan, Y., Vinson, J.A., Etherton, T.D., Proch, J., Lazarus, S.A., \& Kris-Etherton, P.M. (2001). Effects of cocoa powder and dark chocolate on LDL oxidative susceptibility and prostaglandin concentrations in humans. The American Journal of Clinical Nutrition, 74, 596-602.

Wang, J.F., Schramm, D.D., Holt, R.R., Ensunsa, J.L., Fraga, C.G., Schmitz, H.H., \& Keen, C.L. (2000). A doseresponse effect from chocolate consumption on plasma epicatechin and oxidative damage. Journal of Nutrition, 130(8 Suppl.), 2115S-2119S.

Wiswedel, I., Hirsch, D., Kropf, S., Gruening, M., Pfister, E., Schewe, T., \& Sies, H. (2004). Flavonol-rich cocoa drink lowers plasma F2-isoprostane concentrations in humans. Free Radical Biology \& Medicine, 37, 411-421. 